\title{
Effects of a memory aid in probability learning'
}

JAMES R. ERICKSON, JOHN W. O'HARA AND MARI R, JONES OHIO STATE UNIVERSITY

Eighty Ss served in a probability-learning experiment where $\pi(.70$ or .90$)$, instructions (random or problem solving), and memory aid (present or absent) were varied factorially. Mem. ory aid consisted of lights which informed $S$ which events had been correct on the three previous trials. Conditional response probabilities were closer to conditional event probabilities in memory-aid conditions, especially under problemsolving instructions.

It seems clear that in a probability-learning situation the stimulus for any given response must be based on what $S$ remembers about the series of preceding events and what hypotheses, if any, he has about this series. Despite the obvious importance of short-term memory, there have been very few studies directly investigating this aspect of probability learning, although Erickson (1966) showed that interfering with S's memory of a series of events by having him work on four concurrent probability-learning tasks caused overshooting of predictions of the most frequent event $\left[p\left(A_{1}\right)>p\left(E_{1}\right)\right]$. In the present study some Ss were given a memory aid in the form of a display of the three most recent events in the series. Effects on marginal and conditional probabilities were of interest.

Method

The Ss were 80 female students from the introductory psychology subject pool; these Ss participated in experiments to satisfy a course requirement.

An S's display consisted of a standard probabilitylearning setup with a white signal light, two red reinforcement lights below the signal light, and two response levers below the reinforcement lights. In addition, three pairs of lights were located above the signal light which provided information about prior events; the bottom pair showed which event was correct one trial back, the middle pair, two trials back, etc. This information was available at all times, being updated automatically after each trial. Control and monitoring apparatus was located outside the sound-treated room where $\mathrm{S}$ sat. The sequences of stimulus and reinforcement lights were preprogrammed on paper tape and the timing of trials was controlled by automatic equipment. The S's responses were manually recorded by $\mathrm{E}$.

The Ss were randomly assigned to eight groups, $10 \mathrm{Ss}$ per group. The groups represented the cells in a 2 by 2 by 2 factorial: two levels of memory aid, present $(M)$ or absent (NoM); two levels of $\pi=p\left(E_{1}\right), .70$ or .90; and two levels of instruction. The Ss were given instructions either emphasizing problem-solving (PS) aspects of the situation or emphasizing that the sequence of events was random (R). Events were randomized in 100-trial blocks with the restriction that no more than two $\mathrm{E}_{2}$ events occurred in succession. Each S made 300 predictions, with brief rest periods after each 100 -trial block. Sequences used and sequence orders were counterbalanced across conditions.

The timing sequence for each trial was as follows: The signal light came on for $2.7 \mathrm{sec}$ during which time Ss were instructed to respond; after a pause of $1 \mathrm{sec}$ the $E_{1}$ or $E_{2}$ reinforcement light came on for $1 \mathrm{sec}$; the intertrial interval was $3.3 \mathrm{sec}$ during which time the prior-trial display was updated (if it was on for that $S$ ). Results and Discussion

Overall probabilities of an $A_{1}$ response (where $A_{1}$ is the response corresponding to event $E_{1}$ ) by 100-trial blocks are shown in Fig. 1. Analysis of variance of data from the third block showed that the main effect of $\pi$ was highly significant $(F=55.32$, $d f=1 / 72, p<.001)$ and the main effect of instructions approached significance $(F=3.83$, df $=1 / 72, p<.06)$. No other main effects or interactions were significant. It was clear that the memory aid had little effect on marginal response levels.

Examination of conditional response probabilities, however, reveals some important effects of the memory aid. These data are presented in Table 1. Only the data

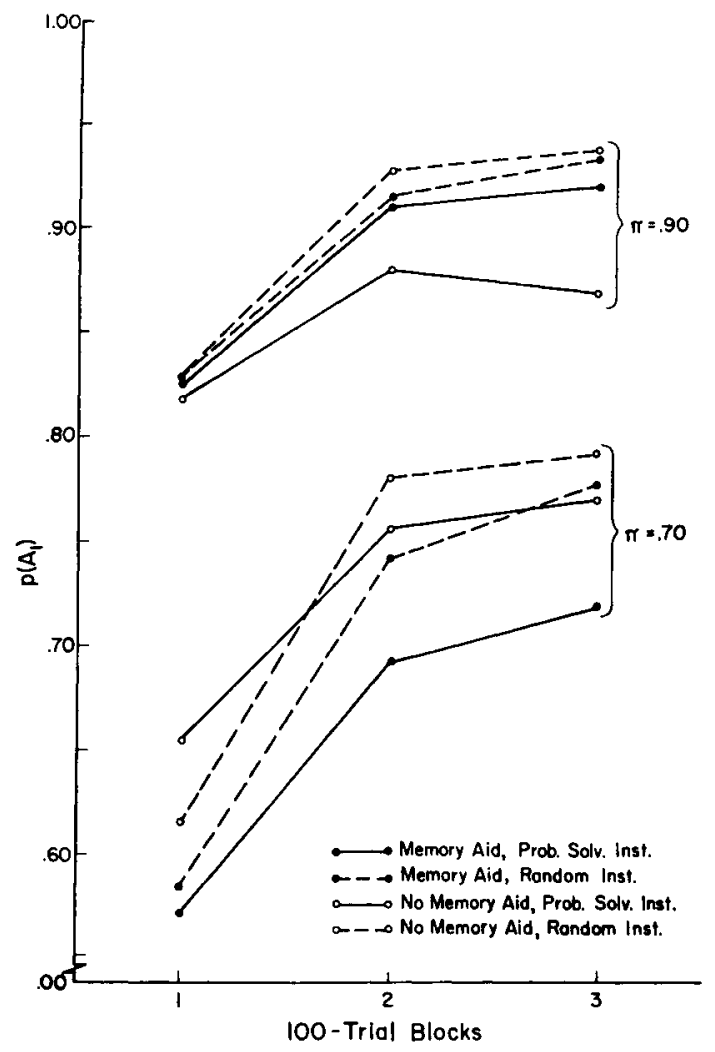

Fig. 1. Probability of an $A_{1}$ response by 100-trial blocks in different conditions. 
from the $\pi=.70$ conditions are discussed here since when $\pi=.90$ the conditional probabilities did not vary enough to be of much interest (because of the "ceiling effect" of high probabilities.). The first column of Table 1 gives the number of trials on which each of the conditional probabilities is based. The remaining columns are self-explanatory.

Two points should be made about these data. First, Ss in the M-PS group more closely approximated the conditional $E_{1}$ probabilities than did the other groups, with the $M-R$ group second. If the $A_{1}$ probabilities are ranked in terms of closeness to the $E_{1}$ probabilities, M-PS is at or tied for Rank 1 in 10 of the 17 cases; M-R is 1 five times; NoM-PS, three times; and NoM-R, zero times. (Data from $\pi=.90$ were similar with the M-PS group at or tied for Rank 1 in 13 of the 17 cases). Second, there was a general tendency to overshoot conditional $p\left(E_{1}\right)$ values. Average deviations from $p\left(E_{1}\right)$ values for the four groups were $.012, .068, .060$, and .088 for M-PS, M-R, NoM-PS, and NoM-R, respectively, all indicating overshooting.

As a final analysis, some of the data were compared with predictions from the N-element pattern model (Atkinson \& Estes, 1963) of stimulus sampling theory. In particular, the two parameters of the model $(\mathrm{N}$ and $\mathrm{c}$ ) were estimated from two of the $p\left(A_{1, n} \mid A_{i, n-1}, E_{j, n-1}\right)$, and the other two conditional probabilities (CPs) were then predicted using these parameters. The fits were quite poor. Table 2 shows parameter values, and predicted and obtained CPs for the various conditions. It can easily be seen that the predicted and obtained prob-

Table 1. Marginal and Conditional $A_{1}$ Probabilities for Various Memory Aid and Instruction Conditions: Data from Trials 201-300 in $\pi$ $=.70$ Conditions

\begin{tabular}{|c|c|c|c|c|c|c|}
\hline Variable & $\mathrm{n}$ & $\mathrm{p}\left(\mathrm{E}_{1}\right)$ & M-PS & $M-R$ & $\begin{array}{l}\text { NoM } \\
\text { PS }\end{array}$ & $\begin{array}{c}\text { NoM } \\
-\mathbf{R}\end{array}$ \\
\hline $\mathbf{A}_{1}$ & 1000 & .70 & .72 & .78 & .77 & .79 \\
\hline$A_{1, n} \mid E_{1, n-1}$ & 696 & .69 & .73 & .81 & .82 & .85 \\
\hline$A_{1, n} \mid E_{2, n-1}$ & 294 & .73 & .68 & .71 & .64 & .64 \\
\hline$A_{1, n} \mid E_{1, n-2}$ & 693 & .67 & .72 & .78 & .74 & .77 \\
\hline$A_{1, n} \mid E_{2, n-2}$ & 287 & .75 & .71 & .76 & .82 & .84 \\
\hline$A_{1, n} \mid E_{1, n-3}$ & 690 & .69 & .69 & .75 & .77 & .76 \\
\hline$A_{1, n} \mid E_{2, n-3}$ & 280 & .71 & .76 & .82 & .74 & .84 \\
\hline $\mathrm{A}_{1, \mathrm{n}} \mid \mathrm{E}_{1, \mathrm{n}-1, \mathrm{E}_{1, \mathrm{n}-2}}$ & 478 & .70 & .75 & .85 & .83 & .86 \\
\hline $\mathrm{A}_{1, \mathrm{n}} \mid \mathrm{E}_{2, \mathrm{n}-1}, \mathrm{E}_{1, \mathrm{n}-2}$ & 215 & .62 & .64 & .64 & .54 & .56 \\
\hline $\mathrm{A}_{1, \mathrm{n}} \mid \mathrm{E}_{1, \mathrm{n}-1}, \mathrm{E}_{2, \mathrm{n}-2}$ & 208 & .65 & .69 & .70 & .80 & .84 \\
\hline $\mathrm{A}_{1, \mathrm{n}} \mid \mathrm{E}_{2, \mathrm{n}-1}, \mathrm{E}_{2, \mathrm{n}-2}$ & 79 & 1.00 & .78 & .90 & .89 & .85 \\
\hline$A_{1, n} \mid E_{1, n-1}, E_{1, n-2}, E_{1, n-3}$ & 333 & .65 & .72 & .83 & .83 & .84 \\
\hline $\mathrm{A}_{1, \mathrm{n}} \mid \mathrm{E}_{2, \mathrm{n}-1}, \mathrm{E}_{1, \mathrm{n}-2}, \mathrm{E}_{1, \mathrm{n}-3}$ & 145 & .65 & .62 & .60 & .54 & .50 \\
\hline$A_{1, n} \mid E_{1, n-1}, E_{2, n-2}, E_{1, n-3}$ & 133 & .63 & .66 & .64 & .80 & .82 \\
\hline $\mathrm{A}_{1, \mathrm{n}} \mid \mathrm{E}_{2, \mathrm{n}-1}, \mathrm{E}_{2, \mathrm{n}-2}, \mathrm{E}_{1, \mathrm{n}-3}$ & \multicolumn{6}{|c|}{ same as $A_{1, n} \mid E_{2, n-1}, E_{2, n-2}$} \\
\hline $\mathrm{A}_{1, \mathrm{n}} \mid \mathrm{E}_{1, \mathrm{n}-1}, \mathrm{E}_{1, \mathrm{n}-2}, \mathrm{E}_{2, \mathrm{n}-3}$ & 135 & .81 & .82 & .88 & .82 & .91 \\
\hline $\mathrm{A}_{1, \mathrm{n}} \mid \mathrm{E}_{2, \mathrm{n}-1}, \mathrm{E}_{1, \mathrm{n}-2, \mathrm{E}_{2, \mathrm{n}-3}}$ & 70 & .56 & .69 & .71 & .54 & .68 \\
\hline $\mathrm{A}_{1, \mathrm{n}} \mid \mathrm{E}_{1, \mathrm{n}-1}, \mathrm{E}_{2, \mathrm{n}-2}, \mathrm{E}_{2, \mathrm{n}-3}$ & 75 & .68 & .73 & .81 & .79 & .88 \\
\hline $\mathrm{A}_{1, \mathrm{n}} \mid \mathrm{E}_{2, \mathrm{n}-1}, \mathrm{E}_{2, \mathrm{n}-2, \mathrm{E}_{2, \mathrm{n}-3}}$ & 0 & - & - & - & - & - \\
\hline
\end{tabular}

Table 2. Predicted and Obtained Conditional Probabilities

\begin{tabular}{|c|c|c|c|c|c|c|c|c|c|}
\hline \multirow{2}{*}{\multicolumn{2}{|c|}{ Condition }} & \multirow[b]{2}{*}{$\mathrm{CP}_{1}$} & \multirow[b]{2}{*}{$\mathrm{N}$} & \multirow[b]{2}{*}{$\mathrm{CP}_{3}$} & \multirow[b]{2}{*}{$c^{a}$} & \multicolumn{2}{|c|}{$\mathrm{CP}_{2}$} & \multicolumn{2}{|c|}{$\mathrm{CP}_{4}$} \\
\hline & & & & & & Pred & Obt & Pred & Obt \\
\hline \multirow[t]{4}{*}{$\pi=.70$} & M-PS & .735 & 8.571 & .649 & .737 & .704 & .727 & .618 & .759 \\
\hline & M-R & .860 & 1.875 & .708 & .315 & .495 & .612 & .327 & .706 \\
\hline & NoM-PS & .840 & 2.143 & .606 & .501 & .607 & .765 & .373 & .724 \\
\hline & NoM-R & .872 & 1.744 & .619 & .441 & .552 & .785 & .299 & .712 \\
\hline \multirow[t]{4}{*}{$\pi=.90$} & M-PS & .925 & 4.000 & .947 & -088 & - & .851 & - & 1.000 \\
\hline & $M-R$ & .946 & 2.174 & .899 & .102 & .533 & .821 & .486 & .800 \\
\hline & NoM-PS & .896 & -25.000 & .872 & $\longrightarrow$ & - & .658 & - & .857 \\
\hline & NoM-R & .945 & 2.222 & .916 & .064 & .524 & .860 & .495 & 1.000 \\
\hline \multicolumn{10}{|c|}{ Note: $\mathrm{CP}_{1}=\mathrm{p}\left(\mathrm{A}_{1, \mathrm{n}} \mid \mathrm{A}_{1, \mathrm{n}-1}, \mathrm{E}_{1, \mathrm{n}-1}\right)=\pi(1-1 / \mathrm{N})+1 / \mathrm{N}$} \\
\hline \multicolumn{10}{|c|}{$C_{2}=p\left(\left.A_{1, n}\right|^{A_{2, n-1}}, E_{1, n-1}\right)=\pi(1-1 / N)+c / N$} \\
\hline \multicolumn{10}{|c|}{$\mathrm{CP}_{3}=\mathrm{p}\left(\mathrm{A}_{1, \mathrm{n}} \mid \mathrm{A}_{1, \mathrm{n}-1}, \mathrm{E}_{2, \mathrm{n}-1}\right)=\pi(1-1 / \mathrm{N})+(1-c)$} \\
\hline \multicolumn{10}{|c|}{$\mathrm{CP}_{4}=\mathrm{p}\left(\mathrm{A}_{1, \mathrm{n}} \mid \mathrm{A}_{2, \mathrm{n}-1}, \mathrm{E}_{2, \mathrm{n}-1}\right)=\pi(1-1 / \mathrm{N})$} \\
\hline
\end{tabular}

${ }^{a} C_{3}$ was used to estimate $c$ because $n$ was greater than for $\mathrm{CP}_{2}$. When $c$ was estimated from $\mathrm{CP}_{2}$ and predictions made of $\mathrm{CP}_{3}$ and $\mathrm{CP}_{4}$, the predictions were also poor, although only in the $\pi=.90$, NoM-PS condition did impossible parameter values result.

abilities are quite discrepant, and that, for two of the $\pi=.90$ conditions, impossible values for the parameters were obtained (negative values for $\mathrm{N}$ or $\mathrm{c}$ ).

In addition, the theory demands that $\mathrm{CP}_{1}$ be the highest of these four conditional probabilities and $\mathrm{CP}_{4}$ be the lowest, with the other two intermediate, their ordering determined by the particular parameter values. In none of the $\pi=.70$ conditions and in only one of the $\pi=.90$ conditions did this ordering hold. "Inversions" of the CP rankings have previously been found when incentives were varied within Ss (Schnorr, Lipkin, \& Myers, 1966) and in discrimination situations (Halpern \& Moore, 1967). It is possible that the memory aid acts as a "cue" making the situation analogous to discrimination learning.

While the poor fit of the data to the N-element pattern model is puzzling, the data are promising enough to suggest this method is useful for further study of memory processes in probability-learning situations.

\section{References}

ATKINSON, R. C., \& ESTES, W. K. Stimulus sampling theory. In R. D. Luce, R. R. Bush, \& E. Galanter (Ed.), Handbook of mathematical psychology. Vol. II. New York: Wiley, 1963. Pp. 121-268. ERICKSON, J. R. On learning several simultaneous probability-learning problems. J. exp. Psychol., 1966, 72, 182-189.

HALPERN, J., \& MOORE, J. W. Two-choice discrimination learning as a function of cue similarity and probability of reinforcement. $J$. exp. Psychol., 1967, 74, 182-186.

SCHNORR, J. A., LIPKIN, S. G., \& MYERS, J. L. Level of risk in probability learning: Within- and between-subjects designs. J. exp. Psychol, $1966,72,497-500$.

Note

1. The research reported in this paper was carried out at the Human Performance Center and was supported by the Aeromedical Research Laboratories, Aerospace Medical Division, Air Force Systems Command, Wright-Patterson Air Force Base, Ohio, under Contract No. A.F 33(615) -2248 with the Ohio State University Research Foundation. Further reproduction is authorized to satisfy the needs of the United States Government. 